\title{
E-COMMERCE IN SAUDI ARABIA: ADOPTION AND PERSPECTIVES
}

\author{
Sadiq M. Sait ${ }^{1} \quad$ Khalid M. Al-Tawil ${ }^{2}$ Syed Ali Hussain ${ }^{1}$ \\ ${ }^{1}$ Computer Engineering Department, Box 5065 \\ College of Computer Science \& Engineering, \\ King Fahd University of Petroleum \& Minerals \\ Dhahran, Saudi Arabia \\ \{sadiq,hussain\}@ccse.kfupm.edu.sa \\ ${ }^{2}$ Director, Network Information Center \\ Ministry of Interior, \\ Riyadh, Saudi Arabia \\ altawil@ccse.kfupm.edu.sa
}

\begin{abstract}
Among one of the most far-reaching influences of the Internet, especially from the perspective of business and market models, is the concept and application of eCommerce. Today, this erstwhile 'experimental' commerce model has become a standard platform for streamlining business flows and broadening product outreach. This is validated by the significant emphasis by a number of countries in developing robust eCommerce architectures tailored to suit their economical-social systems. An interesting case study in this perspective is the Kingdom of Saudi Arabia, especially given its emphasis on local, regional and religious traditions. Presently, with a tremendous growth rate in Internet connectivity, the Kingdom is actively moving towards large-scale adoption of eCommerce systems. In 2001, a two year project was initiated to study the present influence of Internet on social, educational and business systems within the Kingdom. One of the major aspects was the analysis of user responses collected over the two-year period through a number of surveys, which were designed based on two prominent behavioural models: Theory of Planned Behaviour and Roger's Theory of Diffusion of Innovations. The consequent analysis of the results was supported and in some cases verified with linear regression models. This paper reports on the consequent findings, which identify factors that may significantly affect the adoption of eCommerce in the Kingdom.
\end{abstract}

\section{INTRODUCTION}

Modern Saudi Arabia today represents a unique and convergent blend of social conservatism and technological prowess, a tremendous transformation from an isolated, desert land that it was over 50 years ago. Achieving this however has often mandated novel approaches, which strive to merge technology into the existing societal structure and avoid possible confrontations of interest. The growth of the global Internet and its absorption into the mainstream Saudi society has arguably been the most significant of such endeavours. The effort is ongoing as the Kingdom further opens Internet access, exploring opportunities for the Internet in education, government and commerce. The Saudi government has shown increasing interest in pursuing eCommerce systems for promoting national and regional businesses, especially through the structuring of a legal framework for online transactions. Given the Kingdom's regional influence, such a move would very likely impact business flow and commerce systems in the Middle East. This study reports on the factors in terms of both infrastructural support for, and behavioural responses to eCommerce adoption within the Kingdom. As such, it is highly significant as a tool for policy makers and business planners with commercial interests in the Middle East.

Although Saudi Arabia has been linked to the Internet for several years, wide-scale public access to the world-wide-web was initiated in January 1999. Given the unmediated nature of the medium, the main focus areas emphasized achieving effective censorship of inappropriate content without creating any noticeable bottleneck in throughput and access speeds. The technological implementation involved routing all Internet access through a central proxy server at the King Abdul-Aziz City for Science and Technology (KACST) in the capital city of Riyadh. The history of the Internet in the Kingdom and its present architecture are well documented both officially and by independent reviewers (ISU 1998; Tawil 2001).

Over the past decade, the Kingdom has taken measured but strong steps towards developing a diversified economy, with emphasis on developing its Information Technology sector. A core issue 
has been the introduction of robust eCommerce initiatives through out the country spanning both vertical Business-to-Consumer (B2C) and lateral Business-to-Business (B2B) market systems. As of the time of this study, these initiatives are still in the pipeline and haven't yet been fully achieved. However, to realize the afore-mentioned generic market systems, two different sets of variables have to be understood and measured. The first of these deals with the infrastructural prerequisites to adopting eCommerce systems such as ubiquitous Internet access, broadband connectivity, transaction security etc. The second set of variables addresses the social and market response factors, such as acceptance of Internet among general society, inclination towards online transaction systems etc. Given the strongly conservative nature of Saudi society and its gender-based segregation principles, these social variables form an exceedingly unique case study into eCommerce adoption.

In 2001, a research team from the King Fahd University of Petroleum \& Minerals (KFUPM), under a project grant from KACST initiated a comprehensive study of these two interrelated sets of variables. The study, which lasted for two years concluding in 2003, surveyed a wide range of Internet users and businesses regarding their Internet usage, inclination towards eCommerce and existing eBusiness systems if any. The questions and the survey methodology were based on concepts drawn from the Theory of Planned Behaviour (TPB) and Roger's Theory of Diffusion of Innovations (DoI). The resulting model focuses on studying parameters influencing society's response and behaviour. The results were analyzed to determine trends in usage as well as inclination and bias regarding online commerce. These results collectively portray a clear view of factors that will significantly impact eCommerce adoption as Saudi Arabia pursues its IT vision.

The sectional layout of the paper is as follows. The next section provides a review of recent literature on eCommerce adoption in developing countries. Following this, a brief description of the Saudi eCommerce scenario is discussed with reference to the country's present telecommunications infrastructure, Internet access facilities and socio-economic demographics. Then the research methodology is briefly explained with reference to survey implementation, data collection and the respondent profile. The results of the survey are subsequently presented where the findings are supported through linear regression analysis. Finally, conclusions, potential and the various implications of eCommerce deployment in Saudi Arabia are summarized.

\section{LITERATURE REVIEW}

The literature available on eCommerce adoption and diffusion in developed countries is quite extensive and diverse. Numerous studies have been documented that focus on both B2B and B2C domains. The extensive analysis available is not only based on major generic themes like models, strategies, technology and social issues, but also covers specific issues like electronic branding, security, trust, e-payment, performance measures and privacy (e.g., Cronin 2000; Kumar et al. 2000; Plant 2000; Rajput 2000). However, interestingly, the literature documenting eCommerce adoption and growth in developing countries is scarce and often simply anecdotal (Travica 2002; Young 2003). In this section, we report on some of the recent studies in eCommerce that have focused on developing countries.

In 1999 a study reported on e-commerce impediments characterizing Argentina Kenya, India, and Armenia (Petrazzini \& Kibati 1999). These included limited Internet accessibility, a lack of competition in international telephone traffic that made access to the international network expensive, a lack of intra-regional infrastructure, and a disproportionate penetration of the telephone in the urban as opposed to rural, more populated areas. Another study which focused on South Korea identified a major obstacle for eCommerce adoption - lack of customer trust in online merchants (Lee 1999). There is a fear that merchants might sell products with defects, and that online payments cannot be recovered even if the product is not delivered. In central and eastern Europe, online stores may have some design and infrastructure characteristics that are less conducive to success in international e-commerce, such as longer server response time, less inspiring aesthetics, excessive graphics and animation, and lower transactional capability (Travica \& Cronin 1996; Travica \& Olson 1998). 
China, with the highest population, still doesn't embrace ownership innovations (Clark 1999). National networks have been developed through competition between two ministries, which eventually merged into one. As of the writing of the study, B2B transactions had been recorded in mainland China, while B2C systems were still being initiated. The impediments include expensive access, lack of a tradition of remote shopping/selling, lack of trust in product quality, and no provision for customers' recourse.

A similar study covering impediments to eCommerce adoption in Costa Rica, and quite representative of existing conditions in Latin America was carried out in 2002 (Travica 2002). Some of the factors identified were - direct shopping preference, lack of trust for product quality, oral culture, nascent Internet and email culture, infrastructure (limited telecommunication transport and postal services), government monopoly and expensive Internet access. Another interesting and nonobvious obstacle in the delivery of eCommerce goods is the lack of building numbers in the country. Though there are street names in Costa Rica, however, buildings are not referenced with a precisely enumerated location.

In 2002 a study was carried out that reported on limitations for B2B e-commerce in three developing countries, namely Bangladesh, Kenya and South Africa. It was concluded that Internet-based B2B ecommerce is not effective in reducing transaction costs or in providing a gateway to global markets for regional enterprises. Furthermore, this e-commerce model has only marginally altered the way in international businesses dealing in the garments and horticulture sectors, which are these country's main trade areas, deal with one another. The reasons in this case are similar to those seen earlier. The conclusion drawn from these case studies showcases a generic set of factors, the lack of which impedes eCommerce growth and adoption - building trust, ground rules, information infrastructure and maximizing benefits by seamless globalization (Dekleva 2000).

In the case of Saudi Arabia, there has been no study on the adoption and user perspectives about eCommerce. There have been a few efforts that address the issue of Internet penetration in the Middle East in general (Ghashghai 2002). This paper documents the first study working in a broad framework of identifying uses and effects of Internet in the country.

\section{SAUDI ARABIAN E-COMMERCE SCENARIO}

This section briefly documents the present status of Saudi Arabia's demographics and infrastructure and relates them to the perspective growth in eCommerce adoption in the Kingdom.

The strength of the Saudi eCommerce market potential lies in the Kingdom being the centre of the Islamic World with the largest economy ( $\$ 168$ billion) among the Arab countries with virtually no direct taxes. With a high GDP per capita income rated at 9000 Purchasing Power Parity (compared to the regional and global averages of 6167 and 7416) and a high annual population growth rate of $3.4 \%$, Saudi society provides a potentially wide consumer base for commerce and technology driven initiatives. Further, the significant youth population and the presence of large IT companies in the Kingdom give eCommerce a major advantage and a competitive edge regionally (Source: Icon Group International, 2000).

Infrastructure-wise, a key indicator for eCommerce readiness is the extent of Internet access in the Kingdom. According to the most recent estimate by KACST (December 2003), there are 584,000 Internet subscribers in the Kingdom. With an average of 2.5 users per subscriber, the number of Internet users in the Kingdom is estimated at 1,462,000. This represents around $5 \%$ of the complete population. There are currently thirty licensed Internet Service Providers (ISPs) in the country responsible for providing Internet access to businesses and individuals. In the Arab region, this is second only to Morocco, which indicates a strong liberalization policy in this sector. The Kingdom's eighteen educational and related organizations avail direct connection from ISU with an average bandwidth of $2 \mathrm{Mbps}$.

Dial-up connectivity remains the ubiquitous Internet access medium for most individuals, with five million access lines estimated by 2005. Figure 1, which shows the growing teledensity throughout the country, implies a strong telecommunication infrastructure capable of supporting large-scale dial-up connectivity. 


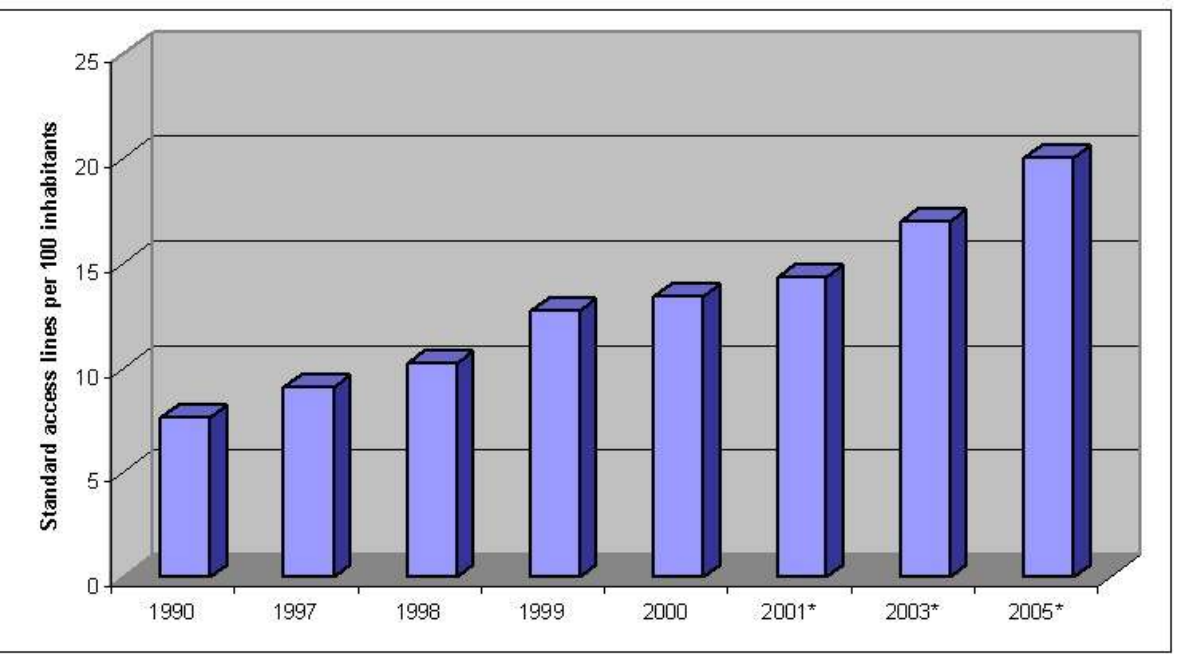

Figure 1: Growth of teledensity in Saudi Arabia (Source: STC, US Census Bureau)

A reliable metric for growth in business-oriented Internet applications is the number of leased lines in the country. These form the main building blocks used by businesses to construct networks capable of supporting high-speed, voluminous eCommerce traffic. Currently, the number of leased lines in the Kingdom is over 10,000 and estimated to reach 30,000 by the year 2005. [Source: Saudi Telecommunications Company (STC)]. Regarding broadband connectivity, the government owned Saudi Telecom Company (STC) as well as private ISPs provide DSL connections for individuals and businesses.

The number of Internet hosts is another commonly referred metric of Internet growth. A host is a domain name that has an IP address 'record' associated with it. Internet surveys of hosts and servers provide one indicator of comparative Internet development between countries. The main limitations in these surveys is the inability to reach all hosts or servers, and the structure of the domain name system being such that there is no guarantee that all hosts under a particular domain are located in a certain geographic location. Among the Arab countries, the UAE tops the list with 59621 hosts with Saudi Arabia recording 10024 hosts. Statistics for other countries in the region are - Egypt: 18706, Lebanon: 7629, and Kuwait: 3188 (ISC, 2001).

However, more relevant to eCommerce growth is the level of security awareness and implementation among individuals and businesses especially in terms of strong encryption measures. Currently there are only seven servers in Saudi Arabia employing strong encryption algorithms (40 bit or more) with four other servers using less robust encryption algorithms (less than 40 bit). This is primarily due to the lack of emphasis on security in the private sector and can be addressed through awareness driven initiatives. Presently, KACST is drawing plans to institute a public key infrastructure (PKI) system that will enable secure Kingdom-wide eCommerce transactions. The Saudi Arabian Monetary Agency (SAMA) is piloting an online payment system for Business-to-Business (B2B) eCommerce based on the widely used 'Society for Worldwide Interbank Financial Telecommunication' (SWIFT) technology. It is also developing a new electronic securities trading system that will deliver straight and transparent processing of payment and share transfers to individual and business entities.

In summary, the overall business environment of the Kingdom gives eCommerce great potential for success, which would position the country as a regional leader. However, to achieve this, Saudi Arabia requires substantial improvements in telecommunication infrastructure with easy and affordable Internet access, while shifting towards broadband connectivity. Further, this infrastructure would have to be supported by trained and skilled local IT professionals to meet the demand for 
human resources in this technology-intensive area. Concurrently, new avenues of imparting the requisite education have to be explored, given the present stress on existing educational institutions. In the next section, the research methodology and the application of theoretical models to survey questionnaire design for the Saudi scenario are discussed.

\section{RESEARCH METHODOLOGY}

\section{Underlying Model}

Adoption models strive to achieve a robust predictability for social response, behaviour towards adoption of new trends and technologies. Most such models pursue a linear approach, wherein progress is defined in stages such as knowledge acquisition, problem framing, decision, implementation and confirmation (Mintzberg et al. 1976; Simon 1977; Rogers 1995). Although some of these models focus only on adoption related activities while taking a black-box approach for the adopter, there has been an increasing trend of incorporating the concept of sense-making into the study. Sense-making is defined as the cyclical process of taking action, extracting information from stimuli resulting from that action, and incorporating information and stimuli from that action into the mental frameworks that guide further action (Seligman 2000). The models using this concept also account for the adopter's mental perceptions and the effect of these perceptions towards his or her adoption of new behaviours.

There are many models that pursue this adopter-centric approach such as Diffusion of Innovations Theory (DoI), Theory of Reasoned Action (TRA), Technology Acceptance Model (TAM) and Theory of Planned Behaviour (TPB). Diffusion of Innovations theory (Roger 1995) identifies the following five characteristics of an innovation that augment its chances of wide acceptance within the population: its relative advantage, compatibility, complexity, trialability and observability. According to this theory, relative advantage is the degree to which an innovation is perceived as better, while compatibility represents the degree to which the innovation is consistent with existing values and customs. Complexity measures the degree to which innovation is considered to be difficult. The last two factors, trialability and observability, measure the degree to which the innovation can be experienced and observed. Theory of Reasoned Action (TRA) (Fishbein et al. 1975) focuses on two independent factors for determining behavioural intention - the attitude towards behaviour and the attitude towards subjective norms. These determinants correspond to behavioural and normative beliefs where the former refers to the extent of the adopter's favourable or otherwise reaction (evaluation, appraisal, etc.) toward a given behaviour while normative beliefs considers the probability that referent persons approve or disapprove of performing a given behaviour. TRA with its robust nature lends itself well to generalization and has been applied to numerous areas including the modelling of technology acceptance (Scannell 1999). Further, it has been used to develop a common frame of reference for comparison of independent research studies (Davis et al. 1989) acceptance of new trends and systems. With the growing global impact of technology on social systems, these models have been widely deployed to study the trends that govern a society's responsiveness and behaviour to this technology's diffusion.

TAM, which is a derivative of the TRA, was designed for the specific purpose of explaining computer-usage behaviour (Davis 1989). Much less general than the TRA, this model incorporates components from Information System literature, and assumes two key determinants for describing technology adoption behaviour - the technology's perceived usefulness and its perceived ease of use. Subjective norms are not taken as significant factors in this model. TAM has been widely used for studying adoption of various technologies from computer usage to eCommerce (Devaraj 2002; Moon 2001; Jiang 2000; Gefen 2000; Lederer 2000).

The TRA model, though has been widely applied in numerous contexts has one chief flaw - it does not address the effect of volitional control on behaviour. The TPB model (Ajzen 1991) compensates for this by assuming three independent factors that influence intention:

- Attitude towards behaviour: This factor, also included in the TRA model represents individual perceptions 
- Subjective norms. This factor represents perceived social compulsion to perform or not to perform the specified behaviour.

- Perceived Behavioural Control. This factor, which distinguishes this model from TRA, represents the perceived ease or difficulty of performing the behaviour and depends on past experience and future impediments.

Each of these determinants corresponds to three types of beliefs: behavioural, normative, and control. These collectively define the individual's intention to perform the concerned behaviour or action. Their extent of influence on intention varies with situation and behaviour; as such all three factors need not necessarily be considered in every context. The TPB model also has been used for studying technology adoption (Scannell 1999). This framework is schematically shown in Figure 1.

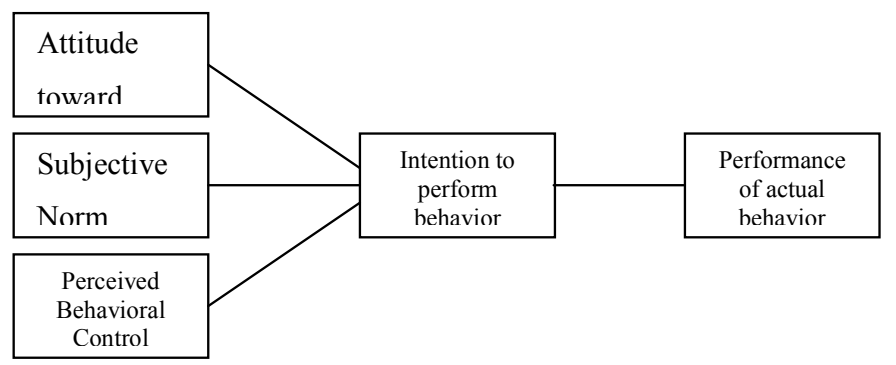

Figure 2: Framework for Theory of Planned Behavior

In this study, the potential for eCommerce adoption in Saudi society and its widespread acceptance is studied using the Theory of Planned Behaviour, which in turn relies on some of the characteristics drawn from the Diffusion of Innovations theory. This contrasts with the majority of other studies which are based on TAM modelling, which concentrates only on 'usefulness and ease-of-use'. The TPB with DoI accommodates both social and non-social factors. Given Saudi Arabia's singular social, traditional and religious values, this approach provides a more robust and valid syntax for modelling behaviour predictions.

\section{Our Approach}

Information gathering in the form of responses to a web-based survey was adopted as the primary medium of data collection. This approach was the obvious choice as the objective was to achieve a representative but random sample of Internet users in the Kingdom. Over 4000 responses were collected. The survey questions were meant to achieve feasible metrics that could properly gauge user responses to eCommerce adoption.

The TPB model, which was briefly described in an earlier section, has been extensively used for predicting behaviour patterns in numerous contexts including technology adoption (Tan 2000; Pavlou 2001; Pavlou 2002). Adapting this model to the Saudi context, a person's intention to adopt eCommerce depends on his attitude towards eCommerce, subjective norms as defined by 'perceived social pressure to adopt or not to adopt eCommerce' and perceived behaviour control defined by 'anticipated ease of using eCommerce'. In the early stages of innovation, subjective norms significantly affect behaviour, as individuals do not have direct experience with the technology. Therefore, the views of friends, family members and other social groups around the individual influence his perception. However, when the individual directly interacts and experiments with the technology, his decisions are directed by his own experiences rather than by the views of others (Tan 2000; Hartwick 1994; Taylor 1995). As the survey was web-based and was directed at Internet users, who would likely have their own individual perceptions from their online experiences and 
information, this study excludes the impact of subjective norms. Only factors contributing to the other two determinants, namely 'Attitude' and 'Perceived Behavioural Control' are enumerated.

The research principle was based on the simple but crucial assumption that if Internet focused business initiatives such as eCommerce and online banking are perceived by individuals and businesses as facilitating economic progress, there would be a much more favourable inclination to adopt these new technologies. Hence the overall objective is to decide which of the above determinants has the most influence on these perceptions. Three characteristics from the DoI theory are included in our model. These include relative advantage, complexity and compatibility. The factors Trialability and Observability cannot be used in this study as eCommerce has not taken off in the country as of yet, and correspondingly survey respondents would not be able to relate to any experiences. The rest of this section below identifies and elaborates on the influencing factors that have been considered in this study.

\section{Attitude towards adoption of eCommerce}

Attitude of the individual is based on his positive or negative views about the intended behaviour, i.e., adoption of eCommerce. The individual develops this perception on the basis of different factors, which are enumerated below (Tan 2000; Tornatzky 1982).

1. The relative advantage of eCommerce on the individual's life, i.e., whether it makes life easier forms a core issue. A realistic assumption is that if an individual believes that eCommerce as a business medium will make life easier then it is quite likely that he will adopt eCommerce. The analysis of all subsequent factors is done against this variable.

2. Practical compatibility of the user with new technology has a positive effect on its adoption (Tornatzky 1982). Therefore factors like long-term computer usage, Internet experience and wider use of Internet services would enhance the chances of adoption of eCommerce.

3. The lower the perceived risk associated with eCommerce services, the higher will be the chances of individuals accepting the technology. This assumption can be supported by considering the argument in a converse manner - Importance given to Internet Security and Privacy by individuals while shopping online can be interpreted as scepticism of Internet services. This would mean that an individual considers online shopping as a high-risk activity, thus resulting in a non-favourable view of eCommerce on the whole. Other studies have also considered security and privacy over the Internet as an impeding factor to the growth of eCommerce (Bhimani 1996).

\section{Perceived Behavioural Control}

Perceived Behavioural Control refers to the anticipated ease or difficulty of performing the said behaviour. In the present context of eCommerce adoption, it refers to the perceived ease and efficiency that users can expect from this new technology. In earlier studies of a similar nature, researchers identified three factors that affect the perceived behavioural control of the individual his confidence in performing the behaviour, facilitating conditions like availability of resources needed to accomplish the behaviour, and the ease of use of technological innovation (Tan 2000; Benham 1996). These three factors are translated into the present eCommerce context as follows:

4 An individual's confidence in his Internet skills adds to the chances of his inclination towards eCommerce.

5 The greater the extent of technological support for Internet, the more likely that eCommerce and home buying will be adopted.

6 Ease of use of home-based or online shopping can significantly enhance chances of eCommerce adoption.

\section{Additional Factors}

Apart from the above two determinants that are part of the Theory of Planned Behaviour, some additional factors have also been identified. Although these do not form a part of the TPB they 
nevertheless add more information to understand the possible effects on user's online shopping and home-based retailing intentions.

7 Gender of Internet surfers may play a significant role in influencing eCommerce adoption in the Kingdom. Given the gender-based segregation policy at all levels of both education and employment, this factor becomes critically important

8 Location of residence can also impact people's perception of eCommerce. Naturally, people living in cities are more likely to adopt home-based online shopping rather than those in rural areas.

9 Tech-savvy individuals, i.e., people comfortable with using new technologies, are more likely to be inclined towards eCommerce. Therefore, wide-scale and extensive use of technological gadgets in a household would be a factor influencing individual intentions regarding eCommerce.

The relative advantage of eCommerce is determined by analyzing responses against the effect of eCommerce on an individuals' life. Except for this 'relative advantage' factor, all other independent factors are analyzed by studying the linear regression between them with 'Effect of eCommerce on individual's life' as the dependent variable. For factors related to practical compatibility, information such as duration of computer usage, Internet experience, number and type of Internet services used by the individual was collected. Further in order to measure the user-perceived risk factor, individual responses on Internet security and Internet privacy were analyzed. If an individual gives less importance to these factors while agreeing to adoption of eCommerce then it shows his confidence in the Internet. In turn, the more confidence one has in Internet as a business and transaction medium, the lower is the risk associated with eCommerce.

Regarding availability of technical support for Internet-related problems, users were queried regarding their satisfaction with their ISP's technical help systems. With regards to the ease of home-based online shopping, user opinion as regards to facilities like easy placing and cancelling of purchase orders, reliable delivery, handling of returns and refunds, easy payment procedures etc were collected.

A number of the factors mentioned earlier were also addressed directly, such as user confidence in their Internet skills, nature of job, education, gender and residence. The technology savvy-ness of users is measured with two metrics - number of computers owned and the number of technology gadgets in his/her household.

Following the above elaboration of factors, the subsequent section reports and discusses the respondent profile and the relevant results seen in the study.

\section{RESULTS AND DISCUSSION}

\section{Respondent Profile}

This section presents a profile of the survey respondents in terms of their age, gender, education, and place of residence. This information presents a platform for extending the survey results to a much larger, macro-level statistical construction of eCommerce adoption trends within an entire society. An essential pre-requisite for such an extrapolation is a reasonably large collection of respondent inputs with an effectively random distribution in terms of their attributes. The survey questionnaire was purely web-based, hosted on a King Fahd University of Petroleum \& Minerals (KFUPM) web server in the public domain. Soliciting respondent input was achieved primarily through banner advertisements on broad-spectrum sites such as those belonging to Internet Service Providers and general-purpose commercial portals. As such, with the absence of any targeted advertising, the set of respondent profiles collected can be considered random. With over 4,000 inputs the statistic results can be justifiably extended to represent expected e-Commerce adoption trends within the entire populace. 

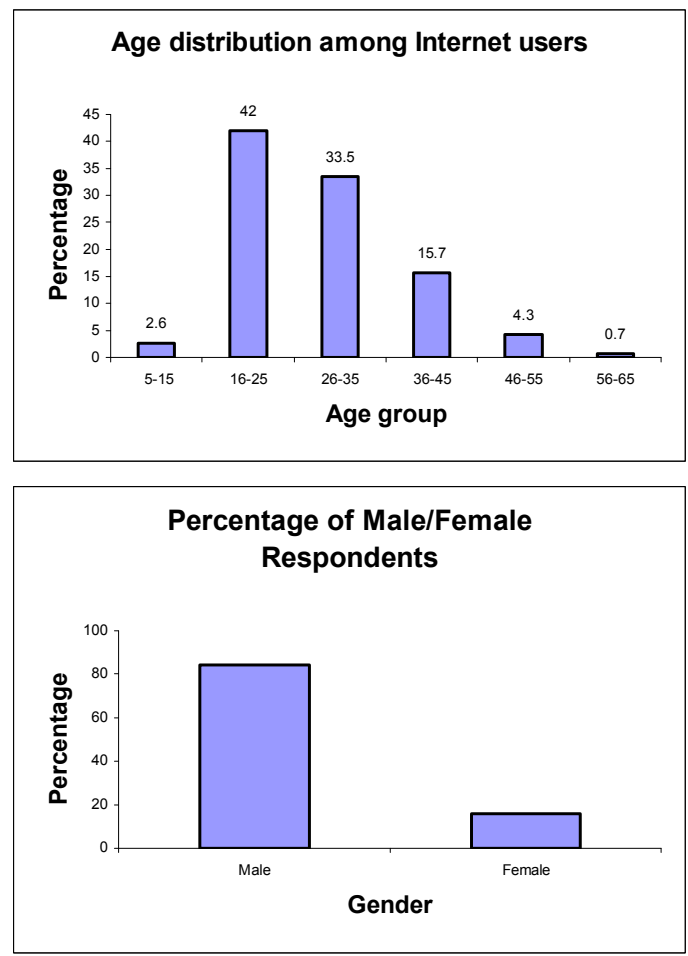

Figure 3: Respondent Profile based on age distribution and gender

Figure 3 presents the respondent profile based on age and gender distributions. It is seen that most of the respondents fall within the 16-35 age groups, thus showing Internet-awareness to be most prominent among the younger and middle-aged generations. The latter graph gains special significance given Saudi Arabia's principles of gender-segregation. As expected here, the number of male respondents considerably outweighs females, a fact that can be attributed to wider access opportunities for males such as Internet cafés, offices etc.

Considering the employment status of the survey respondents shown in Figure 4, it is seen that a significant percentage are students, which serves to support the age group trend seen in Figure 3.

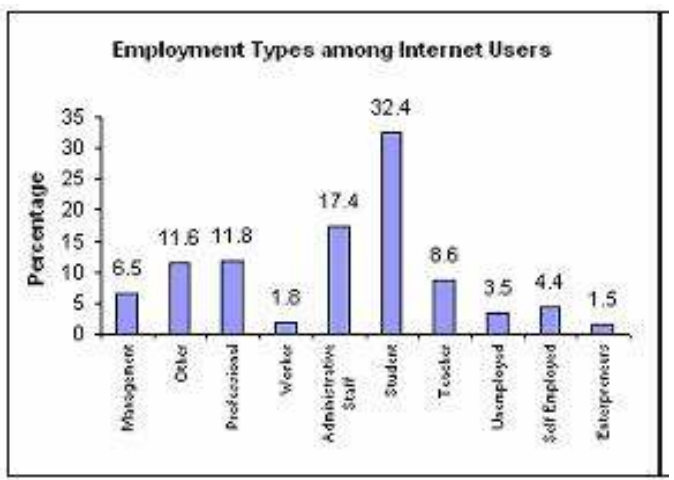

Figure 4: Respondent Profile based on Employment 
Regarding the demographic distribution of respondents as seen in Figure 5, most are from urban areas as compared to towns and rural locations. This is due to the more widely available online access opportunities in cities.

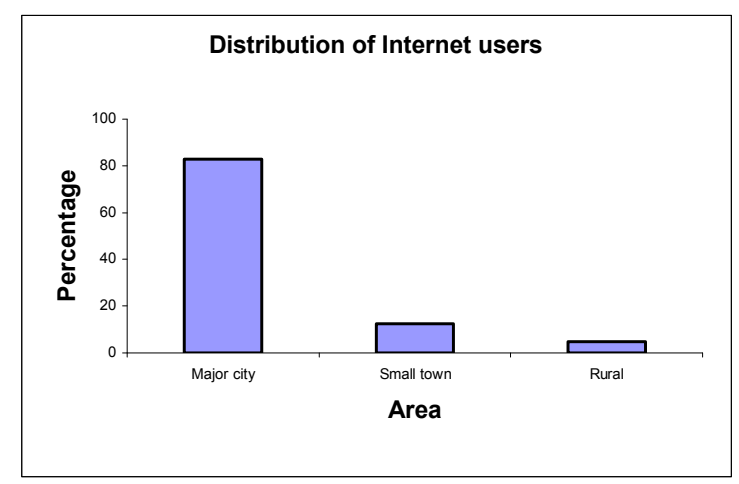

Figure 5: Respondent Profile based on Location

In conclusion, it can be summarized that the respondent profile mainly represents a majority of young males, mainly students and living in urban areas. This adequately models the present population and social structure in the country, with a large segment of the population under thirties. The lack of female and rural respondents can be best gauged as representative of the Internet's nascent status and application in Saudi society. However, these trends will most likely change with the increasing online connectivity in homes and the government's investment in telecommunications infrastructure in non-urban areas.

\section{Results}

Majority of the respondents reported positive views about eCommerce and Internet banking. As shown in Figure 6, 65 \% agreed that the use of Internet for shopping and banking would make life easy while $10 \%$ felt otherwise, with the rest being uncertain. Hence, the conclusion is that the relative advantage of eCommerce and Internet Banking as perceived by Saudi Internet users would favourably effect their inclination to adopt eCommerce. This finding is in line with earlier similar studies reported in literature (Tan 2000; Sia et al. 1998). 


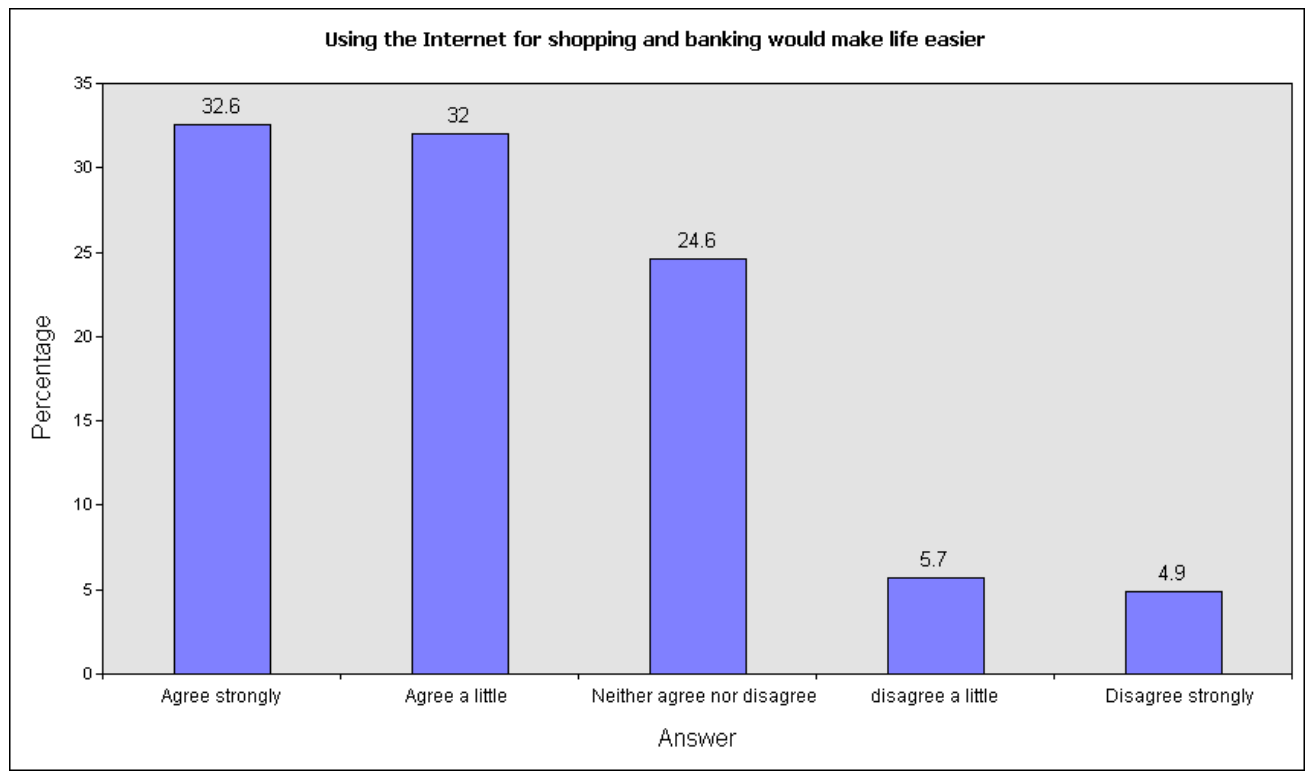

Figure 6: Relative Advantage of eCommerce and Internet Banking on individual's life

For all the other factors, a linear regression analysis was carried out using the statistical software 'Statistica'. A confidence level of $95 \%$ (i.e. $\alpha=0.05$ ) was used. As reported earlier, the analysis of these independent factors is done to identify their effect on adoption of eCommerce based on an assumption that "If use of Internet for Commerce and Banking will make life easier then it is more likely that eCommerce and related services will be adopted".

The results are compiled in Table 1 with the significant $\beta$ values highlighted in bold. Considering the 'Attitude towards eCommerce' determinant, the practical compatibility factor is further broken down into three elements, each of which has a strong significant effect on the adoption of eCommerce. This is because experienced Internet and Computer users, i.e., those who have used the Internet and its wide array of services extensively, are convinced with the importance of eCommerce than those with limited experience. The results are in line with earlier findings where it was reported that increased compatibility with an innovation has a positive influence on individual behaviour (Tan 2000; Tornatzky 1982; Harrington 1999). These three factors - computer usage duration, Internet experience and use of Internet services, are discussed independently below.

\begin{tabular}{|c|c|c|c|}
\hline Classification & Factor & $\mathrm{B}$ & Intercept \\
\hline \multirow[t]{2}{*}{ Attitude } & $\begin{array}{l}\text { Practical Compatibility } \\
\text { a. Computer Usage Duration } \\
\text { b. Internet Experience } \\
\text { c. Use of Number of Internet services }\end{array}$ & $\begin{array}{l}-0.14 \\
-0.24 \\
-0.25\end{array}$ & $\begin{array}{l}2.958 \\
2.943 \\
2.669\end{array}$ \\
\hline & $\begin{array}{l}\text { Risk } \\
\text { a. Importance of Internet Security } \\
\text { b. Importance of Internet Privacy }\end{array}$ & $\begin{array}{l}0.186 \\
0.124\end{array}$ & $\begin{array}{l}1.660 \\
1.827\end{array}$ \\
\hline \multirow[t]{3}{*}{$\begin{array}{l}\text { Perceived } \\
\text { Behaviour } \\
\text { Control }\end{array}$} & Confidence on Internet Skills & 0.205 & 1.702 \\
\hline & Extent of technological support & -0.100 & 2.200 \\
\hline & Ease of eCommerce & -0.35 & 2.477 \\
\hline
\end{tabular}




\begin{tabular}{|l|l|l|l|}
\hline $\begin{array}{l}\text { Additional } \\
\text { Factors }\end{array}$ & Gender & $\mathbf{0 . 1 2 1}$ & 1.748 \\
\hline & $\begin{array}{l}\text { City of residence } \\
\text { Technological Savvy-ness }\end{array}$ & $\mathbf{0 . 0 3 8}$ & 2.086 \\
\hline $\begin{array}{l}\text { a. Number of computers in house-hold } \\
\text { b. Number of tech gadgets in house-hold }\end{array}$ & $\mathbf{- 0 . 1 1}$ & 2.560 \\
\hline
\end{tabular}

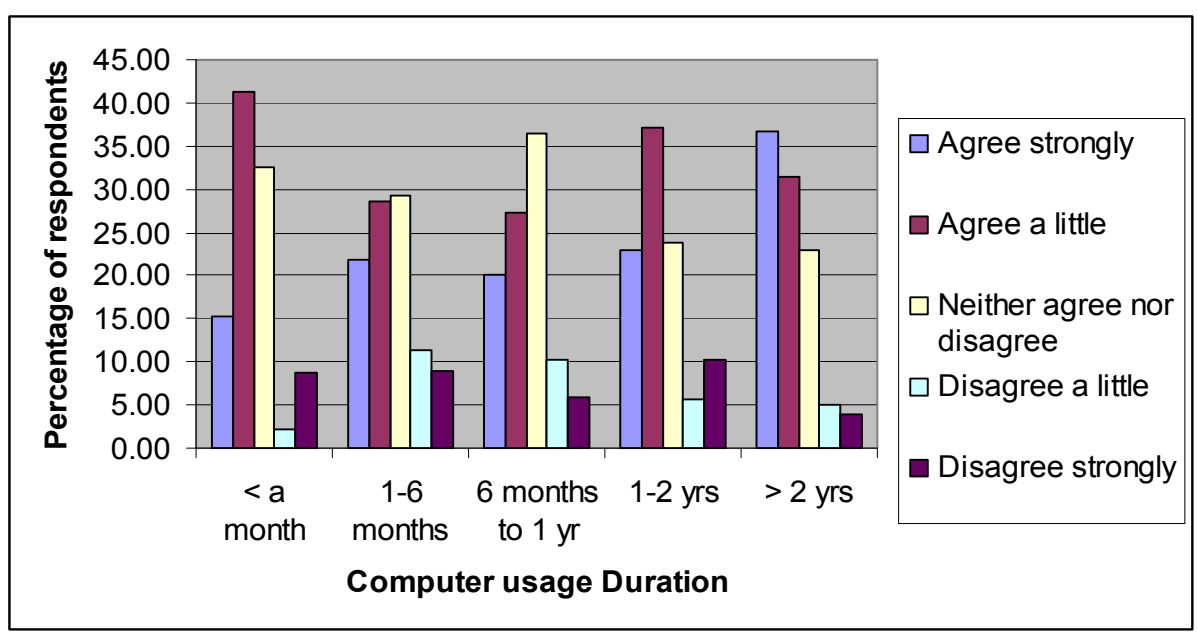

Figure 7: Effect of computer usage duration on adoption of eCommerce

Individuals using computer for longer duration agree more strongly with the argument that eCommerce will make life easier. There is a significant relationship between these two factors with $\beta$ value of -0.14 . It is negative because the computer usage period increases in ascending order while agreement with the argument increases in descending order. This is due to the design of the questionnaire. These two factors are plotted in Figure 7. It is clear from this figure that as the computer usage duration increases, higher percentages of respondents agree that eCommerce will make life easier.

Like other compatibility factors, online experience of an individual also significantly affects his/her inclination towards eCommerce. It means that the more exposure to and consequent experience with the Internet, users would be more inclined towards eCommerce. This conclusion is drawn after analyzing the results of the regression analysis $(\beta=-0.24)$ and the graph shown in Figure 8. 


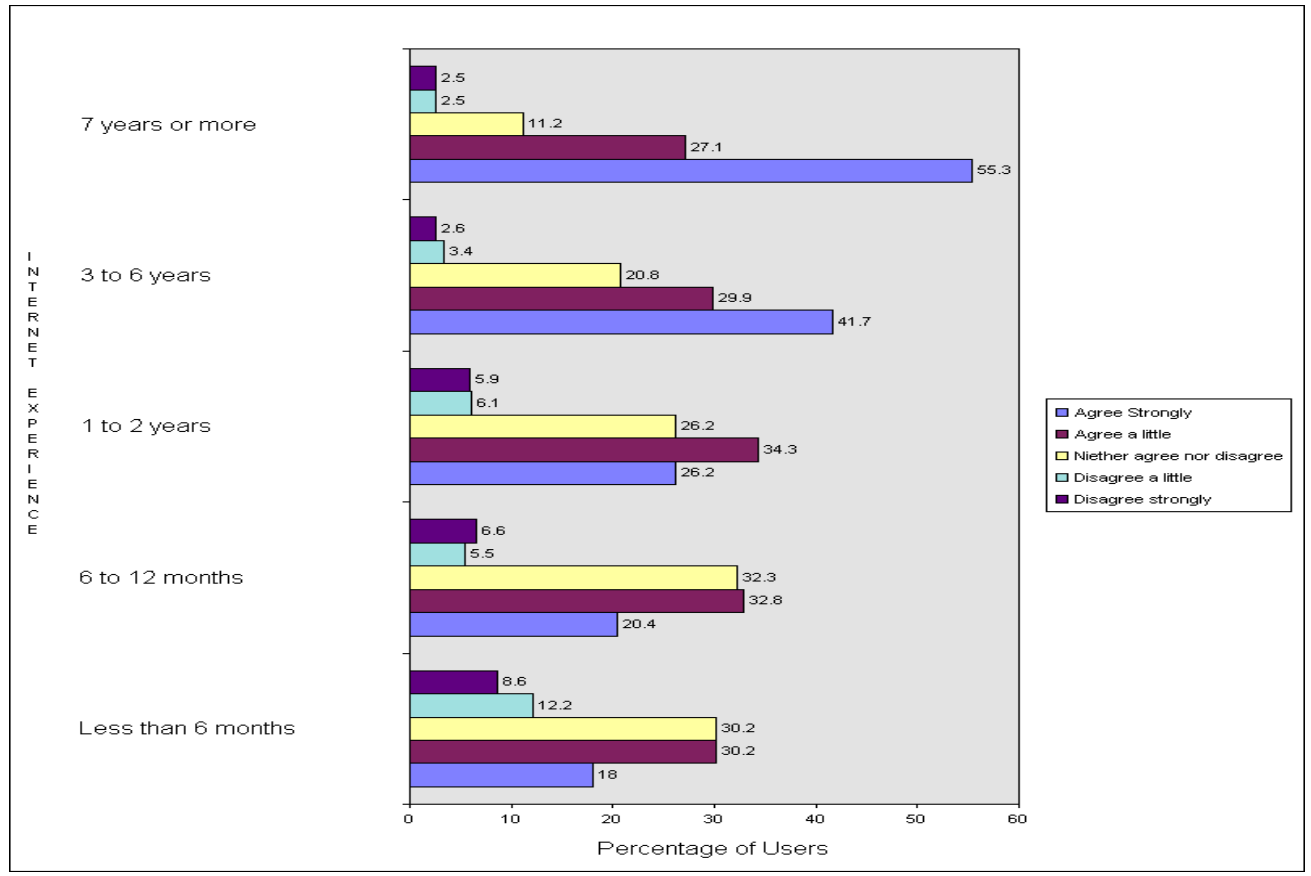

Figure 8: Effect of Internet Experience on adoption of eCommerce

The third compatibility factor is the number of Internet services or operations utilized or performed by the individual. Users who have availed a varying range of Internet services are more likely to embrace eCommerce. The regression analysis shows that there is a significant relationship between these two factors $(\beta=-0.25)$. The corresponding graph shown in Figure 9 also supports this conclusion.

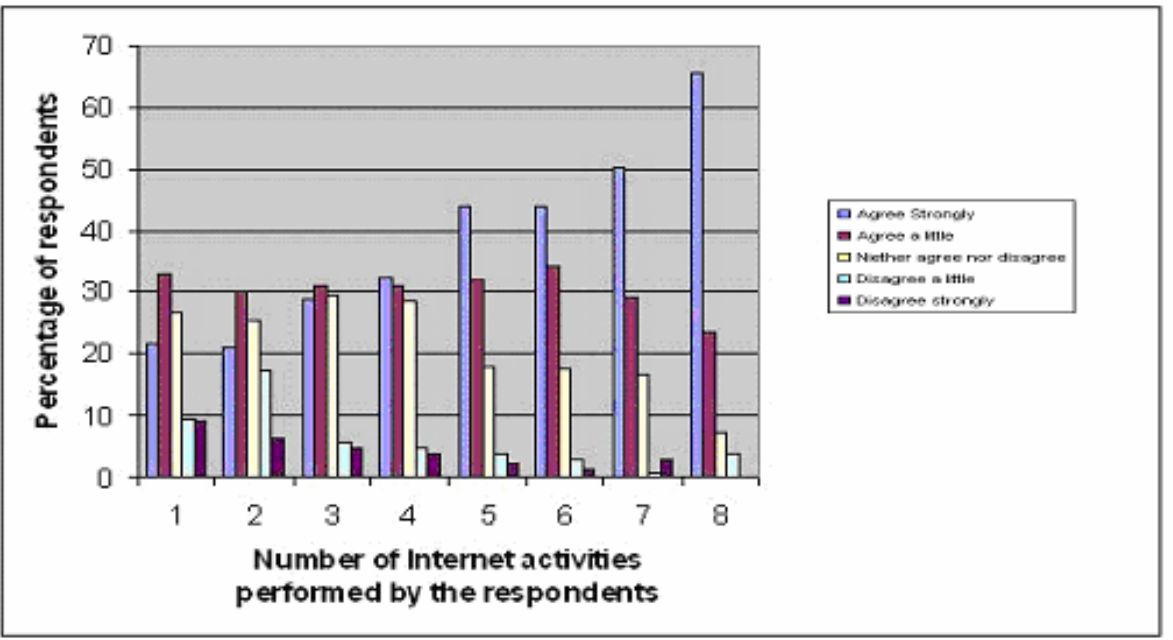

Figure 9: Effect of Use of number of Internet Services on adoption of eCommerce 
User perception of risk associated with the Internet is measured by the importance given by an individual to online security and privacy. Low importance given to these two factors translates into lower perceived risk. Its effect on the adoption of eCommerce is seen through the regression analysis. It reports a significant influence of both security and privacy factors on eCommerce adoption. It is seen that those who give less importance to online security and privacy are confident that the same will not be compromised, i.e., they are confident of the Internet's ability to maintain their security and privacy. But these are the people who are comparatively not eager in adoption of eCommerce. However, those who are serious about eCommerce and online businesses are sceptical of the Internet's ability to maintain their security and privacy and thus are wary of these two factors while shopping online. For successful adoption of eCommerce, user confidence in online security and privacy needs to be enhanced. Hence it can be concluded that security and privacy concerns are obstacles for adoption of eCommerce.

Figure 10(a) and (b) further support this conclusion. Both figures have an almost identical pattern where the bar chart shows that those who don't give importance to privacy and security on the Internet are not strongly in favour of adoption of eCommerce. However, users who are strongly inclined towards online commerce are sceptical of security and privacy. This result is in line with other studies where researchers have pointed the widely reported concerns of security and privacy as impeding factors in the growth and adoption of eCommerce and Internet banking (Bhimani 1996). Moving further on to the analysis of factors under the "Perceived Behavioural Control" determinant, the effect of factors such as 'confidence in Internet skills', 'extent of technological support' and 'ease of eCommerce' are discussed.

The confidence on Internet skills holds a strong significance for the adoption of eCommerce $(\beta=0.205)$. Users who are comfortable with the Internet are more likely to adopt eCommerce as shown in Figure 11. Other studies have also shown similar results where user confidence in a technology had a significant influence on adoption of new innovations (Tan 2000). 


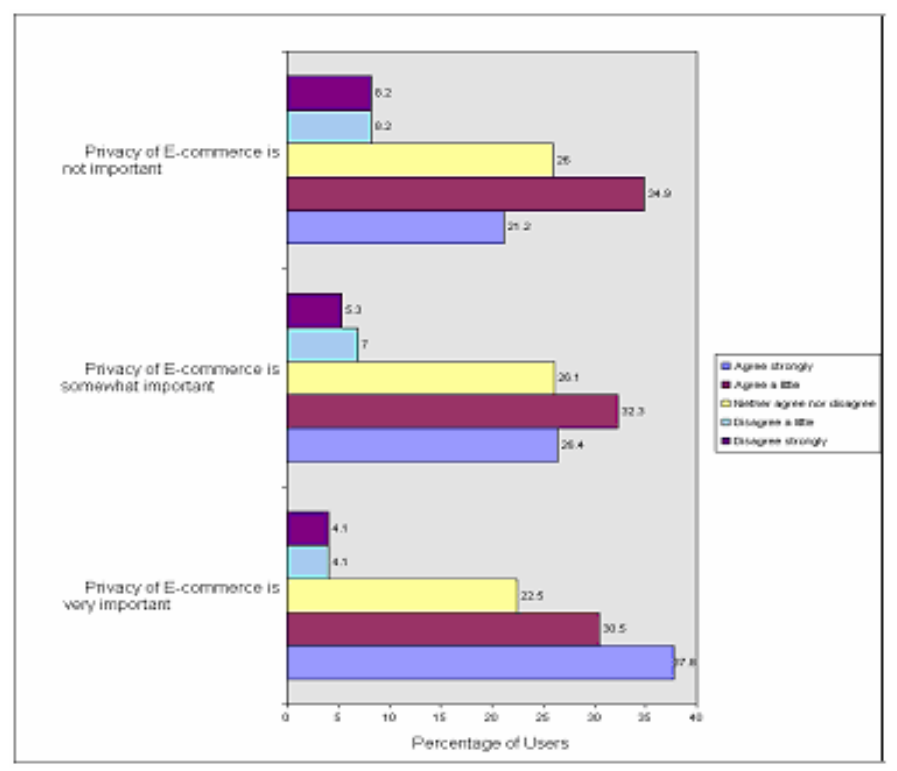

Figure 10(a): Importance of Internet Privacy against eCommerce adoption

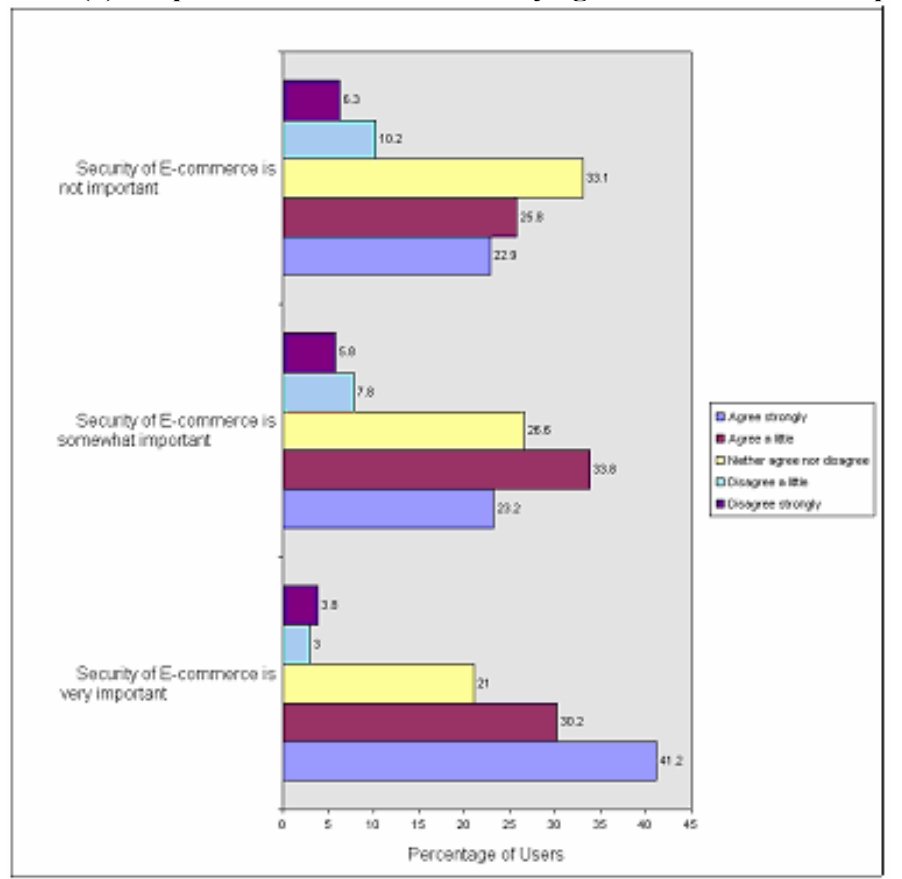

Figure 10(b): Importance of Internet Security against eCommerce adoption

The extent of technological support available to users does not significantly affect eCommerce adoption. There might be many explanations for this behaviour. One possible explanation is that local Internet users in Saudi Arabia are not exactly aware of what technological components or 
building blocks are needed for eCommerce and therefore are indifferent to this important factor. This result is in line with other similar studies in developed countries (Tan 2000). Another plausible reason could be that users view existing technological support as an inherent component of technology services, and hence don't give any significance to this factor.

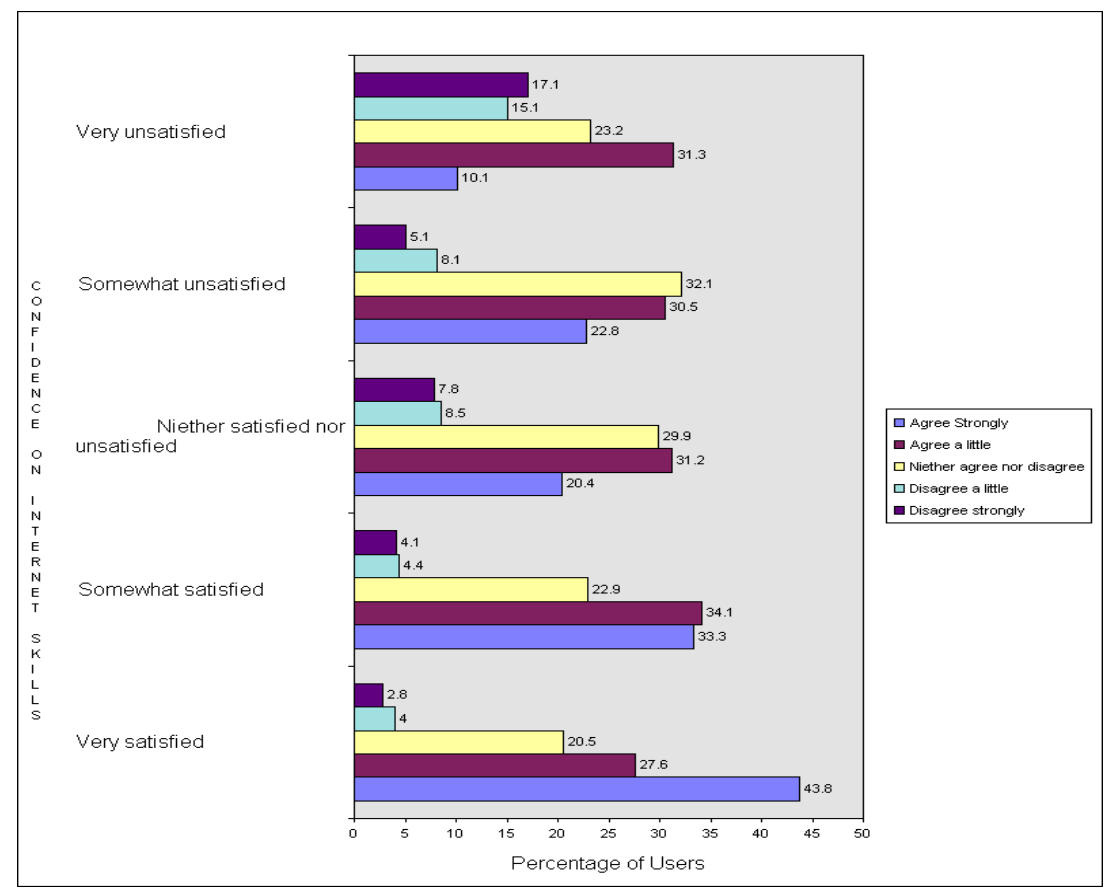

Figure 11: Effect of confidence of Internet skills and adoption of eCommerce

The factors that facilitate application and implementation on eCommerce have significant effect on its adoption $(\beta=-0.35$, Intercept $=2.477)$. Individuals who associate significant importance to ease of eCommerce are more likely to be inclined towards it, as evident from the regression results. The findings are compatible with similar studies available in literature (Benham 1996).

After this analysis of 'attitudinal' and 'perceived behaviour control' factors, the 'additional factors' identified in the research methodology earlier are discussed. These are identified as gender of survey respondent, location of residence and technological savvy-ness. In case of gender, males are more likely to adopt eCommerce than females $(\beta=0.121)$. This behaviour is in accordance with the particular social structure of Saudi Arabia where a majority of women stay at home while earning responsibility lies with the male members of the family. Therefore men find little time for traditional shopping, which often is a significant recreational activity for the women. Therefore, they are less likely to opt for eCommerce. Figure 12 shows the graph generated by cross querying gender and inclination towards eCommerce.

Individuals living in major cities are more likely to adopt eCommerce than those who live in small cities/towns $(\beta=0.038)$. Possible analysis of this finding can be as follows: people living in cities lead busy lifestyles and hence eCommerce is an important facility for effective time-management; also there is a greater likelihood of eCommerce implementation within urban areas given the available infrastructure.

The final factor is technological savvy-ness. This is measured on the basis of two metrics: number of computers and number of technology gadgets in home. As reported earlier, both of these factors have significant effect on intention to adopt eCommerce (Table 1). As the number of computers in a 
household increases, the likelihood of eCommerce adoption also increases. The negative sign in the corresponding $\beta$ value is due to opposite order of these two factors in the survey questionnaire. Similarly, more technological gadgets in household are indicative of a user confidence and comfort with technology; this translates favourably for eCommerce adoption. This result is further supported by the plot of corresponding cross queries as shown in Figure 13.

In this section, the significant factors that influence user intention and subsequent adoption of eCommerce were documented. The analysis was based on a well-known and effective theory of social sciences known as the 'Theory of Planned Behaviour' that draws from Diffusion of Innovations theory (DoI). The TPB model analyzed two determinants namely 'Attitude' and 'Perceived Behaviour Control'. This research methodology was applied on the sample data collected using a web-based questionnaire. The conclusions were drawn on the basis of linear regression and graph plots of corresponding cross queries.

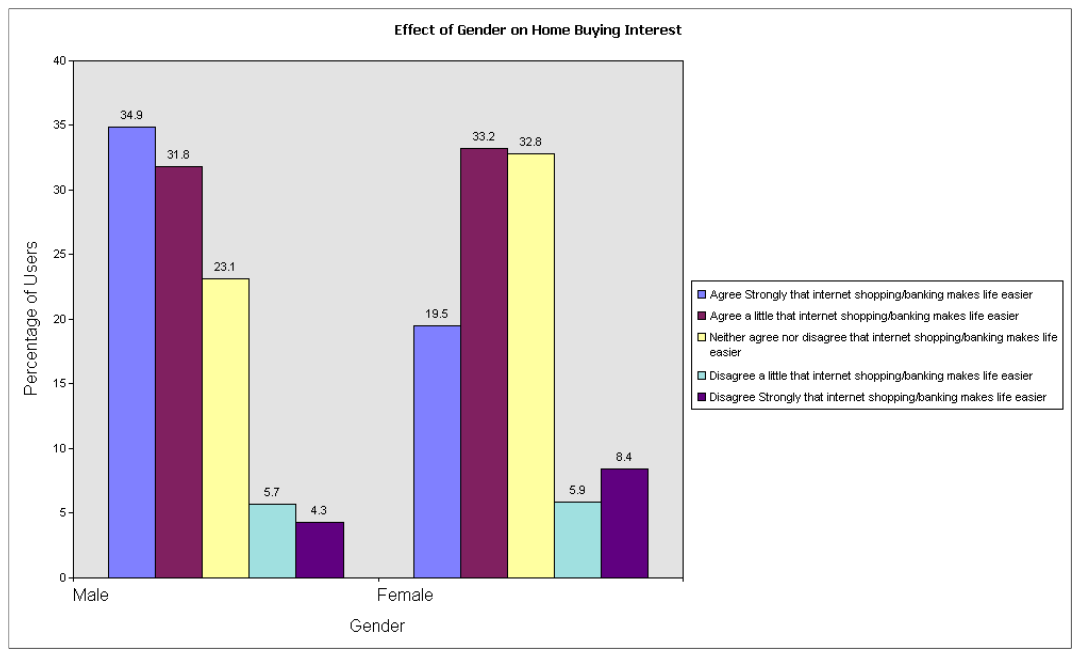

Figure 12: Effect of gender on adoption of eCommerce (home buying) 


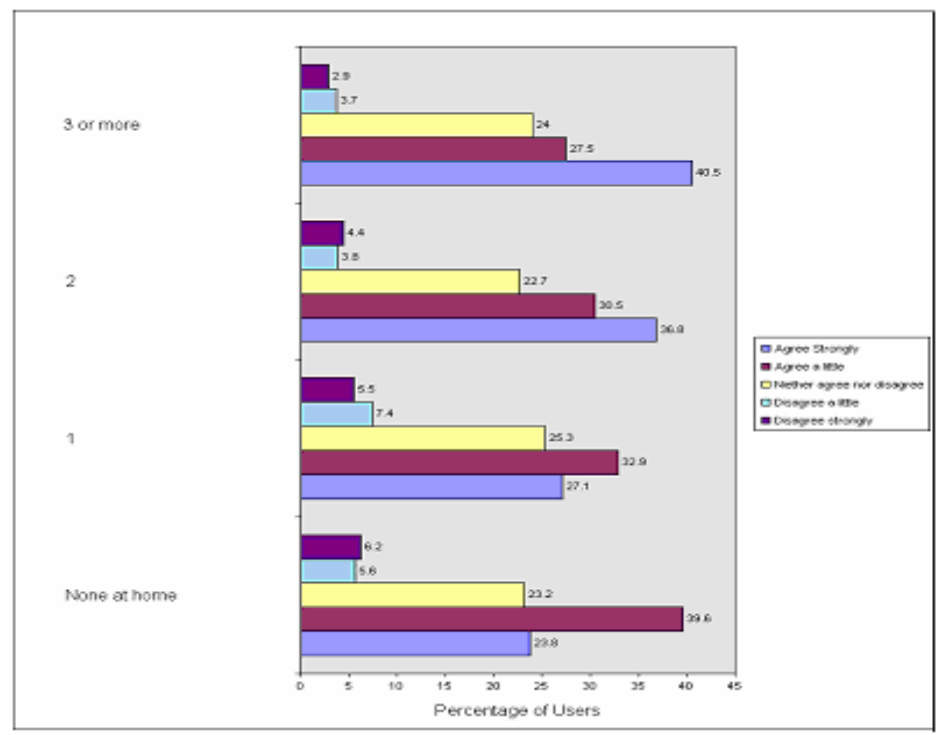

Figure 13(a): Effect of technological savvy-ness on adoption of eCommerce versus number of computers

\section{APPLICATION OF RESULTS}

The essence of the study lies in its providing a framework for identifying key areas crucial to a successful adoption of eCommerce in the country. We define it as a framework, as these focus points may have to be altered and expanded after the eCommerce implementations to adapt to changes. Moreover, given the present nascent status of Internet driven commerce in the Kingdom, especially with the government evaluating large-scale initiatives, this study provides guidelines to policy-makers as well as relevant businesses. The following are the key areas inferred from the above results and analysis:

Internet Access: Internet connectivity within the Kingdom is primarily dialup especially for individuals at homes. There is a need to make broadband connectivity more affordable for the end users as compared to its present costs. At the same time, there is a need to focus on communication infrastructure in non-urban areas. Similarly, the lack of Internet usage among females has to be addressed, primarily through awareness campaigns and lowering of Internet rates. 


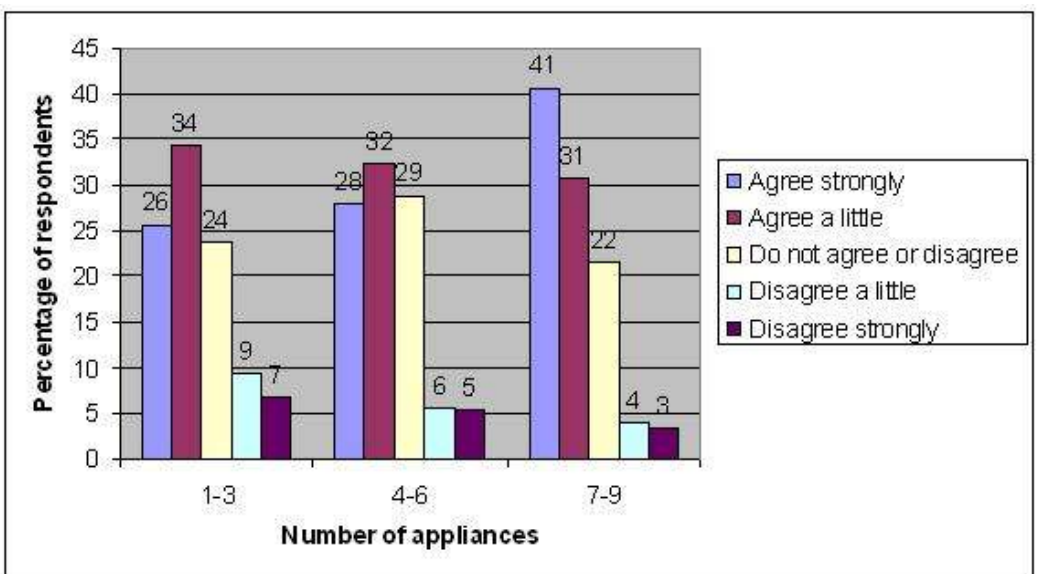

Figure 13(b): Effect of technological savvy-ness on adoption of eCommerce versus number of Tech gadgets in household

eCommerce Facilities: These mainly refer to the need for instituting the required information infrastructure, security of transactions, and a government accountable certification authority and Public Key Infrastructure (PKI) encryption system. Another important aspect is establishing an efficient and reliable postal address system for residences and businesses.

eCommerce Awareness and Promotion: The lack of online exposure within the Kingdom would require awareness and promotion campaigns to enlighten the public about the advantages and applications of eCommerce. Also such a program would serve to dispel myths and concerns regarding security of transactions and privacy of data in turn providing a transparent view of eCommerce operations to the end users.

\section{LIMITATIONS OF THE STUDY}

Any study done on a national scale does have to consider trade-offs between feasibility and accuracy. This may introduce limitations in the results and conclusions drawn as well as variations in the interpretation of data. One such curbing aspect of this study relates to the cross-section of the Saudi population from which the data sample was obtained. Since the survey model was predominantly web-based, the results presented and the inferences drawn pertain to Internet users within the Kingdom and may not apply to a large segment of the Saudi population, which does not have Internet connectivity. However, since this study was conducted in the context of Internet eCommerce, targeting existing online users as the focus group of this study can be considered valid. Since banner advertising was also used to solicit responses, potential biases such as self-selection bias may be inherent in the data. Thus, the findings should be interpreted with caution.

\section{CONCLUSIONS}

This paper focuses on Saudi Arabia's ongoing transition towards the large-scale adoption of eCommerce in the Kingdom. The factors that would most likely influence eCommerce especially within the context of its existing infrastructure, Internet awareness and social and Islamic traditions are elaborated. The work draws on the response of users collected through a web-based survey that lasted for two years. The survey was designed using the 'Theory of Planned Behaviour' to develop metrics for behaviour and attitude towards eCommerce in the

Kingdom. Based on the factors uncovered and analyzed, a brief set of recommendations can be put forth.

It is clear that one of the main focus areas would be to promote wide-scale use of Internet among the populace, both by reducing connectivity cost, enhancing infrastructure and moving towards 
broadband access. eCommerce awareness campaigns should be launched targeting both consumers and businesses. In terms of promoting eBusiness reliability and security, a central Certification authority should be set up with a Public-Key Infrastructure (PKI) encryption system. This would ensure confidentiality and provide access control, integrity, authentication, and non-repudiation services for businesses moving into eCommerce. A legislative framework would also have to be drawn for addressing the issue of online privacy and security.

Achieving these goals in addition to human skill and resources development would require continuous monitoring of progress and inherent flexibility for quick decisions and choices. Hence, a steering committee could be set up drawing individuals both from the government and private business sector to oversee implementation and progress.

\section{ACKNOWLEDGEMENT}

The authors would like to thank King Abdul-Aziz City for Science and Technology under project grant AR-19-16 and King Fahd University of Petroleum \& Minerals for their support. Also the assistance rendered by Salman Khan, Mohammad Wasiq, Syed Sanaullah and Mohammad Faheemuddin throughout the duration of the project especially in the collection, analysis, and documentation of results is highly appreciated.

\section{REFERENCES}

Ajzen, I. (1991), “The Theory of Planned Behavior", Organizational Behavior and Human Decision Processes, Vol 50, pp.179-211

Benham H. C. \& Raymond B. C. (1996), "Information Technology Adoption: Evidence from a Voice Mail Introduction”, ACM SIGCPR Computer Personnel Volume 17, Issue 1, January, pp. $3-25$.

Bhimani A. (1996) "Securing the Commercial Internet," Communications of the ACM, Vol. 39, issue 6, pp. 29-35.

Clark, Ted (1999), "Electronic Commerce in China", chapter in Doing Business on the Internet, Sudweeks and Romm (eds.), Springer, London.

Clark, Ted (1999), "Electronic Commerce in China", chapter in Doing Business on the Internet, Sudweeks and Romm (eds.), Springer, London.

Cronin, Mary J. (2000), “Unchained Value: The New Logic of Digital Business.” Boston, MA. Harvard Business Press.Davis, 1989:

Davis F. D. (1989) "Perceived Usefulness, Perceived Ease of Use, and User Acceptance of Information Technology.” MIS Quarterly, Vol 13, pp. 319-340.

Davis F. D., Bagozzi R. P., \& Warshaw P. R. (1989) "User Acceptance of Computer Technology", Management Science, Vol 35, pp. 982-1003.

Dekleva, S. (2000), "Electronic Commerce: A Half-Empty Glass," Communications of AIS, June, Vol. 3, Article 18. pp 74-80.

Devaraj S., Fan M., \& Kohli R. (2002). "Antecedents of B2C Channel Satisfaction and Preference: Validation e-Commerce Metrics”, Information Systems Research, Vol 13, No 3, pp. 316-333.

Fishbein, M., \& Ajzen, I. (1975) Belief, Attitude, Intention and Behavior: An Introduction to Theory and Research, Reading, MA: Addison-Wesley.

Gefen D. \& Straub D. W. (2000). "The Relative Importance of Perceived Ease-of-Use in IS Adoption: A Study of E-Commerce Adoption", Journal of the Association for Information Systems. Vol, 1No 8, pp.1-27.

Elham Ghashghai, and Rosalind Lewis (2002), "Issues Affecting Internet Use in Afghanistan and Developing Countries in the Middle East," Rand Corporation, IP-231-CMEPP, http://www.rand.org/publications/IP/IP231/index.html

Hartwick J. \& Barki H. (1994), "Explaining the Role of User Participation in Information System Use," Management Science, Vol 40, No 4, pp. 440-465.

Internet Software Consortium (2001), "Internet Domain Survey", http://www.isc.org/ds/. 
ISU (1998), Internet Services Unit, King Abdul-Aziz City for Science and Technology, www.isu.net.sa

Jiang K., Hsu M.K., Klein G. \& Lin B. (2000). "E-Commerce User Behavior Model: An Empirical Study". Human Systems Management, Vol 19, No 4, pp. 265-277.

Harsha Kumar, Fingar, Peter, \& Tarun Sharma (2000), "Enterprise E-Commerce: The Software Breakthrough for Business-to-Business Commerce.” Tampa, FL: Meghan-Kiffer Press.

Lederer A., Maupin D., Sena M. \& Zhaung Y. (2000). "The Technology Acceptance Model and the World Wide Web". Decision Support Systems, Vol 29, No 3, pp. 269-282.

Lee, O.,(1999) "An Action Research Report: A South Korean E-commerce Firm's Case”, Doing Business on the Internet: Its Pitfalls and Opportunities, Sudweeks \& Romm(eds), SpringerVerlag, UK,

Mintzberg, H., Raisinghani D., \& Theoret A. (1976) “The Structure of Unstructured Decision Processes", Administrative Science Quarterly, Vol 21, No 2, 1976, pp. 246-275.

Moon, 2001: Moon, J. \& Young-Gul, K. (2001). "Extending the TAM for a World-Wide-Web Context", Information and Management, Vol 38, pp. 217-230.

Pare, D. J. (2002), "B2B E-commerce Services and Developing Countries: Disentangling Myth from Reality," International Conference on Internet Research 3.0 (AoIR), Maastricht, the Netherlands, October 13-16.

Pavlou, P. A. (2001) "Consumer Intentions to Adopt Electronic Commerce - Incorporating Trust and Risk in the Technology Acceptance Model”, DIGIT Workshop, New Orleans, Louisiana, December 16.

Pavlou, P. A. (2002), "What Drives Electronic Commerce? A Theory of Planned Behavior Perspective," Best Paper, Proceedings of the Academy of Management Conference, Denver, Colorado, August 9-14.

Petrazzini, B., and M. Kibati (1999), "The Internet in Developing Countries," Communications of the ACM, Vol. 42, No. 6, pp 46-57

Plant, Robert (2000), eCommerce: Formulation of Strategy. Upper Saddle River, NJ: PrenticeHall

Rajput, Wasim E. (2000), E-Commerce Systems: Architecture and Applications. Boston: Artech House.

Rogers, E. (1995) Diffusion of Innovations (4th ed.), New York: The Free Press.

Scannell, T.V. (1999) Behavioural Models of Advanced Manufacturing Technology Selection, Thesis, Michigan State University, East Lansing, MI.

Sia, C., Teo, H., Tan B.C. \& Wei K., (1998), "Examining Environmental Influences on Organizational Perceptions and Predisposition toward Distributed Work Arrangements: A Path Model”, Proceedings of the International Conference on Information systems (ICIS), Helsinki, Finland, pp. 88-102.

Simon, H. (1977) The New Science of Managerial Decision Making, Englewood Cliffs, NJ: Prentice Hall.

Tan, M., \& Teo, T. S., (2000), "Factors Influencing the Adoption of Internet Banking", Journal of the Association for Information Systems, Vol 1, Article 5, pp. 1-42.

Tawil, K. M. (2001), "The Internet in Saudi Arabia", Telecommunications Policy, Elsevier Publications, Vol 25, Issue 8-9, pp. 625-632.

Taylor S. \& Todd P. A. (1995), "Understanding Information Technology Usage: A Test of Competing Models”, Information Systems Research, June, pp. 144-176.

Tornatzky L. G., \& Klein K. J. (1982), "Innovation Characteristics and Innovation AdoptionImplementation: A Meta-Analysis of Findings", IEEE Transactions on Engineering Management, Vol 29, No 1, February, pp. 28-45.

Travica, B (2002), "Diffusion of Electronic Commerce in Developing Countries: The Case of Costa Rica," Journal of Global Information Technology Management, Vol 5, No 1, pp: 4-24.

Young, J and Ridley, G (2003): "E-Commerce in Developing Countries," EJISDC, 11, 1, pp: 1-6.

Travica, Bob, \& Blaise Cronin (1996), "The Business Web in Russia: Usability for the Western User,” Proceedings of the AMCIS 1996 Conference, October 21-24, Baltimore, MD.

Travica, Bob, \& Rebecca Olson (1998), "Usability of Business Web Sites in East and Central Europe," Proceedings of the AMCIS 1998 Conference, October 24-29, Pittsburgh, PA. 